\title{
Nutrition education in Scottish schools
}

\author{
Notes taken B Y M. E. J. LEAN (Secretary, Nutrition and Health Group) \\ from a presentation by MOIRA MCFA RLA NE. H.M. Inspector of Schools (S.E.D. \\ Secondary Education), and from subsequent discussion amongst the Nutrition and Health Group
}

It is always reassuring to learn of something about which the nutrition experts are in complete accord. One such absolute truth seems to be that nutrition is very difficult to teach. A second is that the resulting or associated learning process is often incompletely or imperfectly accomplished.

When we think of 'education' there is a tendency to restrict our thinking to those occasions when the all-knowing impart of their store of wisdom, in the hope that this will achieve some amendment of life-style. We think of media campaigns, of texperts in magazines, of disquieting articles of varying degrees of authenticity in newspapers. We think about teachers and schools and indeed nutrition education in the formal curriculum.

Nutrition has had a place within the formal school curriculum for many years but its inclusion has too often been ad hoc and uncoordinated. Most primary schoolchildren have been well warned about the dire consequences of eating sugar. Relatively few. by comparison, have heard about the positive advantages of eating a healthy diet. Arguably too late, we have introduced all secondary schoolchildren to the concept of dietary balance in biology and home economics without helping them to develop the skills of decision-making or the self confidence which will enable them to exercise choice. Not surprisingly, many pupils have not learned well. They have passed examinations but they have not learned. For, if learning is successful then the learner will have reflected on new knowledge, will have measured it against what he or she knows already, will have accepted and rejected different parts of the new knowledge, and will have amended his or her behaviour accordingly.

Notwithstanding 'passes' in Scottish Certificate of Education examinations in food and nutrition, biology and anatomy, physiology and health, all medical experts have told us and continue to tell us that the most important translation of what people know, into what they do about eating, has not taken place. National health statistics may include some hopeful recent trends but by and large they still confirm that nutrition education has not been very effective. Two factors more than any others seemed to contribute to poor learning. The first of these was a tendency to divorce nutrition education from the context of eating behaviour and to present our agenda of sound nutritional principles rather than starting from where the children are. The second is to divorce nutrition education from health education.

\section{FORMAL NUTRITION EDUCATION IN SCHOOLS}

The place of nutrition education is now being re-examined. As to the relative position of nutrition education north and south of the border, the main messages are the same but the priority and modes of delivery through the secondary curricula will be different. 
There will also bc differences in the accessibility of nutrition education to all children. Importantly, a National Curriculum operates in England and Wales, whereas in Scotland curricula are planned at school level on the basis of a broad set of nationally agreed principles.

In England and Wales, provision of health education has been mapped out within the National Curriculum, the main location for nutrition education being science. All pupils will study science but not all pupils will study home economics or personal social education as neither discipline forms part of the compulsory core curriculum. The 'banker' for nutrition education is the science curriculum.

In Scotland, nutrition education in primary schools forms a natural part of health education within environmental studies, one of five major strands in the primary curriculum (language, mathematics, environmental studies, creative aspects and physical education). In many primary schools, nutrition education will occur at more than one point in the curriculum Primary 1-Primary 7. Where the school adopts a sequential health education curriculum such as 'Health for Life' (Health Education Authority, 1989) or uses a planned curriculum structure, e.g. 'Health Education Framework' (Strathclyde Regional Council, 1989) a planned progressive approach to nutrition education will be achieved. Where planning for health education is done on an annual rather than a whole-school basis, nutrition education is more likely to be piecemeal. It is likely that a review and development group currently looking at environmental studies will include in its overall recommendations some proposals for the location of certain aspects of nutrition education within the primary curriculum. In the past there has been a tendency for an imbalance in nutrition knowledge between the sexes since girls have traditionally tended to study home economics. This has not been so in Scotland for some time now, since in an overwhelming majority of Scottish schools all pupils study home economics for the first 2 years of secondary education, as part of a common curriculum. This position may be further improved by introducing nutritional topics in a less formal way to all children at primary school level.

In Scottish secondary schools, home economics at S1 and S2 (12-14 years) provides the most secure location for nutrition education for all, with good contributions also being made in science, social education and physical education. In addition to learning about nutrition, pupils have the opportunity to develop skills in choice and decision-making, acquire the practical skills of healthy food preparation and will have the opportunity to consider attitudes and values associated with health, food and eating. In S3 and beyond (14+ years) some pupils will continue with a more specialized study of nutrition through national award-bearing courses in home economics (Scottish Examination Board, 1987, 1989), biology (Scottish Examination Board, 1990) or health studies (Scottish Examination Board, 1988).

\section{INFORMAL NUTRITION EDUCATION THROUGH SCHOOLS}

Children, even at the age of 5 years, bring to school a vast experience of eating. They will know of eating as a social and sometimes as a solitary activity. A time of family harmony or of discord; food will have been used as a reward and in some cases withdrawal of food as punishment. Children will have experienced food and eating as part of life's celebrations; at birthdays, weddings, and as a solace. Religious and cultural patterns of eating will already have been established. Nutrition education which is not set securely 
within the context of pupils' experience will almost certainly be unsuccessful. It will become compartmentalized and detached from the reality of life-style. At worst it may be discarded as irrelevant. This occurs when teaching is incompatible with the commonplace examples set in the home by parents, grandparents and others whose role in nutrition education is often underrated.

When children come to school first, they will have fairly limited scope for choice in their diet. Early nutrition education must take account of home circumstances and be sensitive to the danger of causing conflict between what the child is taught at school and the ongoing experiences at home. Starting from where the children are, the aim is to 'make things a little bit better' by considering dietary modifications which are within the child's power to effect. Recognition of the eating styles of young children (Rousseau, 1984 ) is important, irrespective of whether they reflect innate or accultured behaviour (Thomas, 1991).

As children grow older their capacity for exercising choice in diet becomes greater. Families are more likely to take their views into consideration in planning meals, they have more money to spend and more freedom in which to spend it. By early teens peer pressure is at its height. Nutritionists, however dedicated and well meaning, must accept that there comes a stage in every child's life when 'socially acceptable people eat at McDonald's. Cruditées cut no ice at teenage parties! Nutrition education must, therefore, not only seek to improve knowledge, but also must provide opportunities for the development of skills in making choices, taking decisions and managing peer pressure.

Nutrition education will not be effective if it is approached in isolation from health education. Good nutrition is after all only one of several factors which go together to make people well physically, socially and emotionally. Particularly important in this respect is the extent to which the school is or is not a health-promoting school. However good the nutrition education is in the classroom, it is unlikely to be effective if it is inconsistent with what is sold in the canteen or the tuckshop, or it appears that the school does not value the health of individuals in its community. In many cducation authorities, catering services are now contracted out and from the viewpoint of the school meals service, balance has to be met between providing healthy school meals and the economic pressure to see what the children, as consumers, want to buy. The alternative is that children will simply disappear to local fast-food outlets. This is an issue of concern to parents, teachers and nutritionists alike, and one which was highlighted in the recent Department of Health and Social Security report on the diets of British schoolchildren (Committee on Medical Aspects of Food Policy, Sub-committee on Nutritional Surveillance, 1989). Whilst the foods consumed by British schoolchildren are adequate for normal childhood growth and development, the total fat intake is $38 \%$ of all energy, with chips and crisps the major food source, providing as much as $17 \%$ of this fat. The worst dicts in this respect are those of teenagers, especially girls, and particularly those who eat lunch out at a cafe. Their fat intake reached $40 \%$ of energy at lunch, with the lowest intakes (at lunch and overall) of protein, calcium, iron, retinol, carotene, thiamin, riboflavin and nicotinic acid, compared with intakes of children who had lunch provided at school or at home. Fruit eating is a rarity for many children, and the overall pattern of eating seems likely to be leading another generation towards high risks of heart disease. 


\section{CONCLUSIONS}

What is now offered in schools then is a broad brush approach developed progressively from 5 to 14 years of age, with more specific study for some aged over 14 years. The approach advocated for primary schools and early stages in secondary schools is to create a growing understanding of the relationship between diet and health. To relate personal eating habits to current national nutritional recommendations such as National Advisory Committee on Nutrition Education (1983) or Department of Health and Social Security (1984) is the first stage in setting attainable targets for making things better. There are many good resources around with which to encourage pupils to consider the pressures on them in terms of food choice and the options open to them for choosing well.

The aim is to equip future generations with the knowledge and skills to eat well on the basis of broad nutrition principles. This is seen as being far more important for all pupils than a decontextualized skill in reciting discrete nutrient requirements which typified the former approach to nutrition education. It is important for teachers to explore behind the words used in nutrition education, to reach the understanding of the child. The detailed study of individual nutrients and their contribution to human well-being is now more likely to be confined to specialist courses in home economics and biology offered at the middle-senior stages in secondary school. At these stages, the study of discrete nutrients can be supported by an understanding of the background through scientific investigation and analysis. The pupil is also more ready to deal with the abstract concepts which emerge in a more detailed study of nutrition.

\section{REFERENCES}

Department of Health and Social Security (1984). Diet and Cardiovascular Disease. Committee on Medical Aspects of Food Policy. Reporr on Health and Social Subjects no. 28. London: H.M. Stationery Office.

Department of Health and Social Security (1989). The Diets of British Schoolchildren. Committee on Medical Aspects of Food Policy, Sub-committee on Nutritional Surveillance. Report on Health and Social Subjects no. 36. London: H.M. Stationery Office.

Health Education Authority (1989). Health for Life 1: A Teacher's Planning Guide to Heallh Education in the Primary School. Health Education Authority Primary Schools Project 1989. Walton-on-Thames, Surrey: Thomas Nelson.

National Advisory Committee on Nutrition Education (1983). A Discussion Paper on Proposals for Nutritional Guidelines for Health Education in Britain. London: Health Education Council.

Rousseau, N. (1984). Bites and Picces. PhD Thesis, University of Edinburgh.

Scottish Examination Board (1987). Scottish Cerificate of Education (SCE) Standard Grade. Revised Arrangements in Home Economics 1987. Dalkeith. Midlothian: Scottish Examination Board

Scottish Examination Board (1988). Scottish Certificate of Education (SCE). Arrangements for Health Studies Short Courses 1988. Dalkeith. Midlothian: Scottish Examination Board.

Scottish Examination Board (1989). Scottish Cerificate of Education (SCE) Higher Grade. Revised Arrangements in Home Economics 1989. Dalkeith. Midlothian: Scottish Examination Board.

Scottish Examination Board (1990). Scottish Certificate of Education (SCE). Arrangements in Biology at Standard Grade and at Higher Grade 1990. Dalkeith, Midlothian: Scottish Examination Board.

Strathclyde Regional Council (1989). Health Education Curricular Framework 1989, pre-5 to post-16. Strathclyde: Strathclyde Regional Council.

Thomas, J. (1991). Food choices and preferences of schoolchildren. Proceedings of the Nutrition Society $\mathbf{5 0}$, $49-57$. 